\title{
Energetic sustainability of the building substitution: the rewards and the facilitations of the Italian Piano Casa
}

\author{
V. Sapienza ${ }^{1}$, A. Gagliano ${ }^{2}$ and R. Chiaramonte ${ }^{3}$ \\ ${ }^{1}$ Department of Architecture \\ DARC, University of Catania, \\ viale Andrea Doria 6, città universitaria - 95125 Catania (Italy) \\ e-mail: vincenzo.sapienza@darc.unict.it \\ ${ }^{2}$ DII, University of Catania, \\ viale Andrea Doria 6, città universitaria - 95125 Catania (Italy). \\ e-mail: agagliano@diim.unict.it \\ ${ }^{3}$ Professional engineer \\ via Monreale 23 - 95123 Catania (Italy) \\ e-mail: chiaramonte.roberta@gmail.com
}

\begin{abstract}
The residential building estate of a large part of the Italian cities is formed by poor quality buildings. In fact, until the last decades of the past century, the current standards were lower than the actual ones (with regards to the structural safety, the indoor comfort, the thermal plants, etc). Moving to the more suburban part of the city, it is possible to see how the high quality of the urban landscape of the city centre vanishes therefore the substitution of the buildings becomes more convenient than the refurbishment, as it is possible to obtain high standards in an easier way.

To promote this type of actions, the Italian Government has introduced a group of regulations, called the "Piano Casa". With the Piano Casa is possible to obtain an enlargement of the building volume during the reconstruction of residential buildings. The Sicilian Regional Government, with the adoption of these regulations in its jurisdiction, has introduced some further advantages which can be obtained using various topics of energy sustainability in the design.

The authors, in the present work, have developed this subject through the cases of a multifunctional building.
\end{abstract}

\section{Key words}

Building sustainability, building substitution, energetic standards.

\section{Italian laws and energy efficiency}

The energetic sustainability is a recent argument, in fact, it was introduced in ' 70 years in consequence of the petroleum crisis. Its application in building sector was successive and, for some aspects, it is still no near a solution.

In Italy the evolution of this subject is very similar to those in the other countries [1]. The first Italian law, regarding the energy saving, was approved at the end of the 1970s (L.N. 373/76). It was useful exclusively to reduce the heat transfer of the building envelope. In the early 1990s another law was passed regarding the efficiency of the heating systems (L.N. 10/90). Since the middle of 2010 attention was directed to the insulation of the roof and external walls and to the set up of heating systems, without any particular influence on the architectonical design. Moreover, only recently the attention has been partially directed to the summer period, which is stronger for the southern countries. In particular consider that in Italy a large part of the country is situated in the hotter climatic areas (Fig. 1).

The European dir. 2002/91/CE represents a main step, in this direction [6]. It is addresses the introduction of the Energy Performance Certificate. In it you can find advice to take into account the position and the orientation of buildings and the natural ventilation. In Italy it was rolled out after many years of delay, with the D. Lgs. 192/2005, amended and completed by D. Lgs. 311/2006. The aim of the law is plain: you must take under consideration this problem in the early steps of the architectonical design and it is not enough to limit your attention to the control of the heating systems. But the indications of the law are only qualitative and not binding. The European and national framework drives regarding this aim considering the local building regulation.

Recently the Sicily Government has approved a really valid and forward-looking regulation. In fact it has adopted the Piano Casa, a technical tool by designed to promote the renewal of the urban landscape, introducing some further advantages which can be obtained using various topics of energy sustainability in the design. These, called bio-architectonic items, are grouped in five 
thematic areas: energy, water, materials, waste and health.

\section{A. The Italian Piano Casa}

The Piano Casa has been introduced in Italy in 2009: it consists of a set of legislative measures and economic incentives designed to simplify the refurbishment of the existing buildings (for several uses), through the extension of individual units and the substitution of the buildings. The main purpose of the Piano Casa is to revitalize the economy through building activity, by promoting extraordinary measures related to existing buildings. So it is aimed to the following goals:

- reduction of seismic and hydrogeological risks;

- requalification of architectural quality;

- implementation of energy efficiency.

The Piano Casa is addressed to the owners of buildings with specific typological characteristics. By it one can obtain a tax reduction, incentives for measures to improve the energy performance of the buildings and premiums in volume.
This agreement between the State and the Regions includes the two following types of actions, on the existing building.

- Expansion: this action is related to houses for one or two families, with volume not exceeding $1000 \mathrm{~m}^{3}$; it is possible to increase the existing volume up to $20 \%$.

- Demolition and Reconstruction: these actions allow the demolition and reconstruction of only residential buildings, with a possible extension of $25 \%$ of the existing volume (for buildings for commercial use it is allowed only demolition and reconstruction, without increase in volume).

\section{B. The Piano Casa in Sicily}

The adoption of the Piano Casa in Sicily, has taken place with the regional law 23/03/2010 n. 6. With it has been enhanced the topic of the sustainability of the new buildings. In fact you can get an additional bonus of $10 \%$ of building volume, adopting a series of actions in the project. These actions are related to the following five areas: energy, water, materials, waste and health (Tab. I)

Table I. - Five area actions of the Sicilian Piano Casa.

\begin{tabular}{|c|c|c|c|}
\hline \multicolumn{2}{|c|}{ AREA } & ACTIONS & $\begin{array}{l}\text { USED IN THE } \\
\text { PROJECT }\end{array}$ \\
\hline \multirow{8}{*}{1} & \multirow{8}{*}{ Energy } & - use of high-efficient boilers or mixing or condensing, or of biomass boilers; & 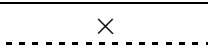 \\
\hline & & use of low temperature radiators on wall, floor or ceiling; & \\
\hline & & use of controlled ventilation systems with heat recovery; & $x$ \\
\hline & & use of geothermal heat pump technology; & \\
\hline & & - passive behavior of the building for summer cooling, by reducing the thermal load; & $\times$ \\
\hline & & - passive behavior of the building for winter heating, with the use of direct and indirect passive solar gain; & $x$ \\
\hline & & - radiant systems integrated with dehumidification controlled systems and use of solar cooling technology; & $x$ \\
\hline & & - reduction of electricity consumption through the use of renewable energy sources. & $\times$ \\
\hline \multirow{3}{*}{2} & \multirow{3}{*}{ Water } & - use of systems for collection, storage, filtration and distribution of rainwater for non-food or sanitary use; & $\times$ \\
\hline & & - use of systems for the rescue, treatment, storage and distribution of gray waters; & \\
\hline & & - use of saving systems in the distribution of water (drinkable and for sanitary use). & $\times$ \\
\hline \multirow{4}{*}{3} & \multirow{4}{*}{ Materials } & - using of environmentally friendly materials or certificated materials; & $x$ \\
\hline & & use of local materials; & $x$ \\
\hline & & use of dry construction techniques; & \\
\hline & & - use of materials and construction techniques that allow low energy consumption. & $\times$ \\
\hline \multirow{3}{*}{4} & \multirow{3}{*}{ Rubbish } & - evaluation and organization of the space used for the collection of differentiated waste; & \\
\hline & & - use of recycled or recyclable materials; & \\
\hline & & - use of materials and construction techniques that allow selective demolition and material recovery; & $\times$ \\
\hline \multirow{6}{*}{5} & \multirow{6}{*}{$\begin{array}{l}\text { Health } \\
\text { and } \\
\text { comfort }\end{array}$} & - limitation of the level of the electric and magnetic fields and the high frequency in the indoor spaces; & \\
\hline & & - noise reduction regarding the technological systems or continuous and discontinuous sources; & \\
\hline & & Q use of materials with good insulation, sound absorption, high vapor permeability and hygroscopic characteristics; & \\
\hline & & - use of materials and products with no or low emission of radioactivity; & $x$ \\
\hline & & - use of high-efficiency lamps with automatic adjustment of light intensity; & $x$ \\
\hline & & - evaluation of adequate levels of natural light in all spaces occupied mainly during the day. & $\times$ \\
\hline
\end{tabular}

\section{The project}

We have studied the possibility of application of the Piano Casa on a specific case study: the design of a residential building. It is located in the A+ class, a not common event for the local architecture, thanks to the attention put on the constitution of the external envelope and thanks to passive and active systems that use renewable energy sources.
Furthermore the combination of used devices lets its built volume go as far as it is possible, thanks to the prize of the Piano Casa.

\section{A. The energy sustainability}

Every aspect of the design of the case study was addressed to minimize the energy consumption, starting from the choice of the type of the building: the terraced house. In fact the garden in front of it, if it is not large, is 
able to lower the external temperature, so improving the comfort conditions.

The internal arrangement is studied to have the best orientation for the more used rooms (the living rooms and the bed-rooms): that is the south-west.

In this way you can control the sunlight and the natural lighting, and also the night ventilation. This is very useful to remove the heat from the mass of the building nvelope, so cooling the indoor space.

According to this aim the walls are built with a masonry in one body of clay bricks, completed with a coat insulation. Thanks to their big surface weight, the walls are really efficient in the summer, the most critical period in the region with Mediterranean climate. In fact they have a really good values for the offset temperature and for the attenuation of its peak. With the coat insulation, in addition to the reduction of the transmittance of the whole surface of the walls, it is possible to correct the thermal bridge, so reducing the dispersion in the winter season (Tab. II).

Table II - Thermotecnical parameters of the building

\begin{tabular}{|c|c|c|c|}
\hline \multicolumn{2}{|c|}{ SUMMER PARAMETER } & \multicolumn{2}{c|}{ WINTER PARAMETER } \\
\hline $\begin{array}{c}\text { Superficial } \\
\text { density }\end{array}$ & $\begin{array}{c}\text { Attenuation } \\
\text { factor: } 0.145\end{array}$ & $\begin{array}{c}\text { Thermal } \\
\text { transmittance }\end{array}$ & $\begin{array}{c}\text { Th. bridge } \\
\text { correction }\end{array}$ \\
\hline $233 \mathrm{Kg} / \mathrm{m}^{2}$ & $\begin{array}{c}\text { Phase shift: } \\
11.60 \mathrm{~h}\end{array}$ & $0.39 \mathrm{~W} / \mathrm{m}^{2} \mathrm{~K}$ & $15 \%$ \\
\hline
\end{tabular}

The glassed part of the vertical envelope is realized with wood-aluminum casement windows: the thermal break aluminum profile is covered by wooden staves, in the internal side, to improve the aesthetic look. Here there are utilized IG with one reflective glass (the treated face is exposed inside the IG, to preserve it). In this way it can reduce the incoming sunlight. For the same goal it was studied a shading system, formed by an outer sliding blind.

On the south-west side there is a group of solar greenhouses; it is possible to open their doors one by one or all together. The horizontal shading system is a brisesoleil, made with photovoltaic panels as slats (Fig. 1).

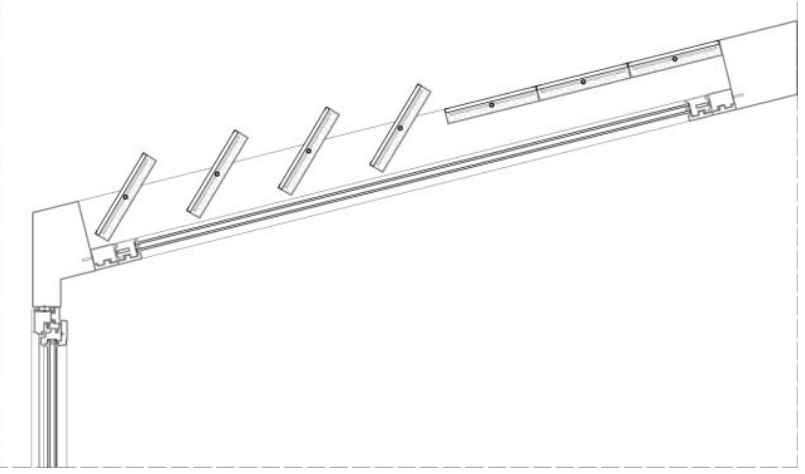

Fig. 1. Brise-soleil system.

During the winter you have to close the doors and to open the brise-soleil. So the heat, captured by the greenhouse, can be transferred inside, with energetic advantages (Fig. 2) [5] [8].

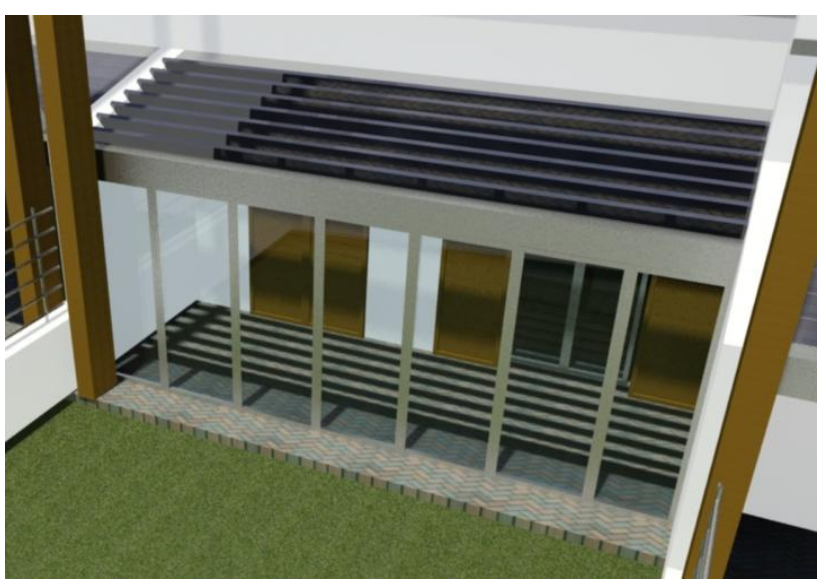

Fig. 2. Greenhouse: winter configuration.

In the summer you must open totally the glasses, and close the brise-soleil. So the greenhouse can become an open "veranda" that is able to make shade and cool to the back rooms (fig. 3).

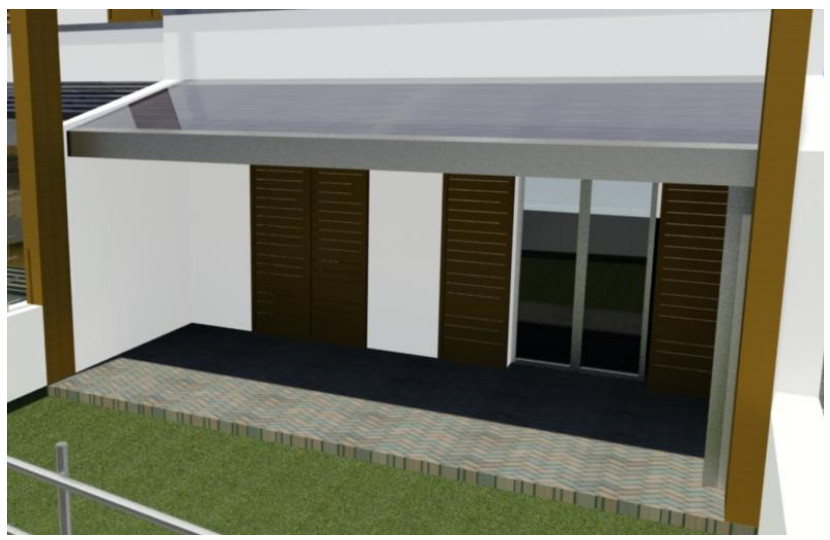

Fig. 3. Greenhouse: summer configuration.

Thanks to this contribution, the greenhouses are connected with the living rooms, that are the most frequented rooms of the house.

The horizontal part of the building envelope is partially a green roof (Fig. 4-5). It has an aesthetic role and offers numerous environmental and economic advantages. In fact it is a very good thermo-acoustic insulation and it has a little cooling effect for the neighboring rooms.

The other portion of the roof of the building is a ventilated wooden arch structure (Fig. 4-6). It has also a climatic role, because it reduces the temperature difference between internal and external spaces [2].

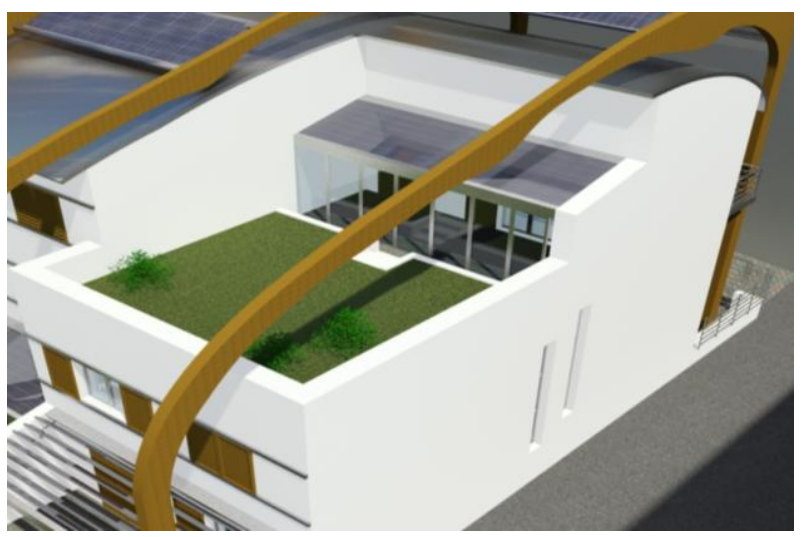

Fig. 4. Building's floors. 


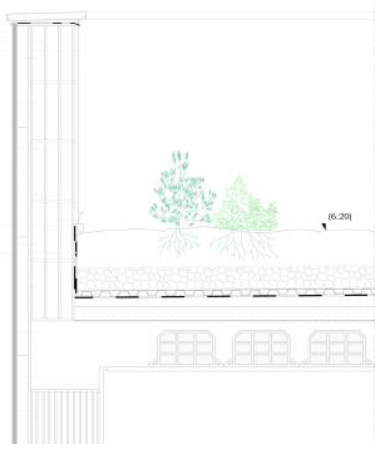

Fig. 5. Green roof's construction detail.

\section{B. The location}

The project is located in Catania, a typical Mediterranean, South-European city. It is situated on the foot of the highest volcano of the continent, the Etna Mountain, and it is extended for a large stretch of the Sicily coast, with his long waterfront, running from the southern beach of the Plaja, low and sandy, as for as the lava cliffs of the Ulisse port, in the village of Ognina. To the west, the city center of eighteenth century, mixes with more recent parts that gradually have given origin to the vast open suburbian town towards the Piana, the plain surrounding the city. This place connecting the ancient town and the modern city, is particularly interesting, for the combination of private homes of various types (from to multifloor buildings to the small isolated villas), shops and public services.

Unfortunately, against this urban structure, so rich and exciting, the buildings its made of are often of poor quality, from an architectural, constructive point of view. The goal of the Piano Casa is precisely to redevelop this type of urban landscape, by facilitating the building owners with incentives for the replacements operations.

\section{Organization of the building}

In particular the area chosen for the project is located along the Mario Rapisardi boulevard, a very long axis that cuts the city for four kilometers from east to west. The area is quite rectangular $(63 \times 23$ meters $)$.

At the present here there are a group of mono or bifamiliar houses, a baker and a little market. No one of these buildings is relevant or quite interesting from an architectural point of view and they have numerous pathologies and superfetations. Moreover they were built before the birth of the modern technique rules regarding the antiseismic device and the energy saving; so they have very low standards from these points of view.

In the project the old buildings have been replaced with one multifunctional building. The volume ratio of the original uses (residential and commercial; Fig. 7-8) has been preserved, without significant variations, in the new building.

The residential part is a three floor terraced building. It is formed by four similar blocks with three apartments for each one. They are different for the surface and for the collocation. Two houses are double floor, ground floor and first floor; the third flat is at the top of the building (the second floor; fig. 9).
The doors of the duplex apartments look to the north-east side, on the little garden; on the ground floor you have: the living room, the kitchen, the lavatory and a second bathroom. On the up floor you have the bed rooms and the main bath room.

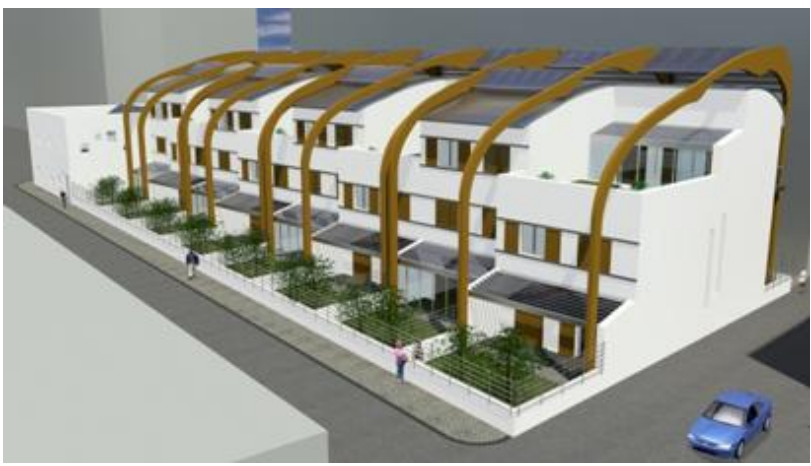

Fig. 7. Residential block.

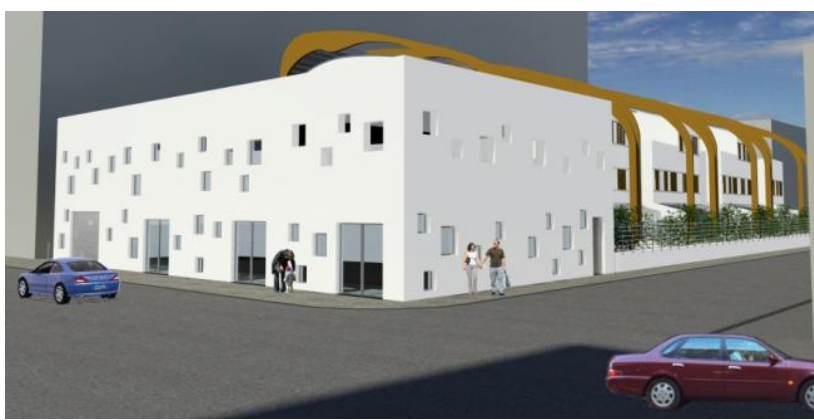

Fig. 8. Commercial block.

In the little garden you have the solar greenhouses. As to the third apartment, it is a gallery house, in which the doors open along a steel suspended gallery (on the northeast side), reached by two external spiral staircases. In this house you can find the living room, the kitchen, the bed-rooms, the bathroom, the laundry and the closet. The green roof, that covers the terraced house below, becomes a little garden for this house. The commercial block (Fig. 10) is located at the end of the row of the houses, along the boulevard. On the ground floor you have three shops. One of this, the fast food is on two floors, with a large open terrace.

There is a garage on two underground levels, for the owners of the flat. The system is mechanized and computerized.

The owner as just to leave his car in a parking area and insert the badge into the reader. 

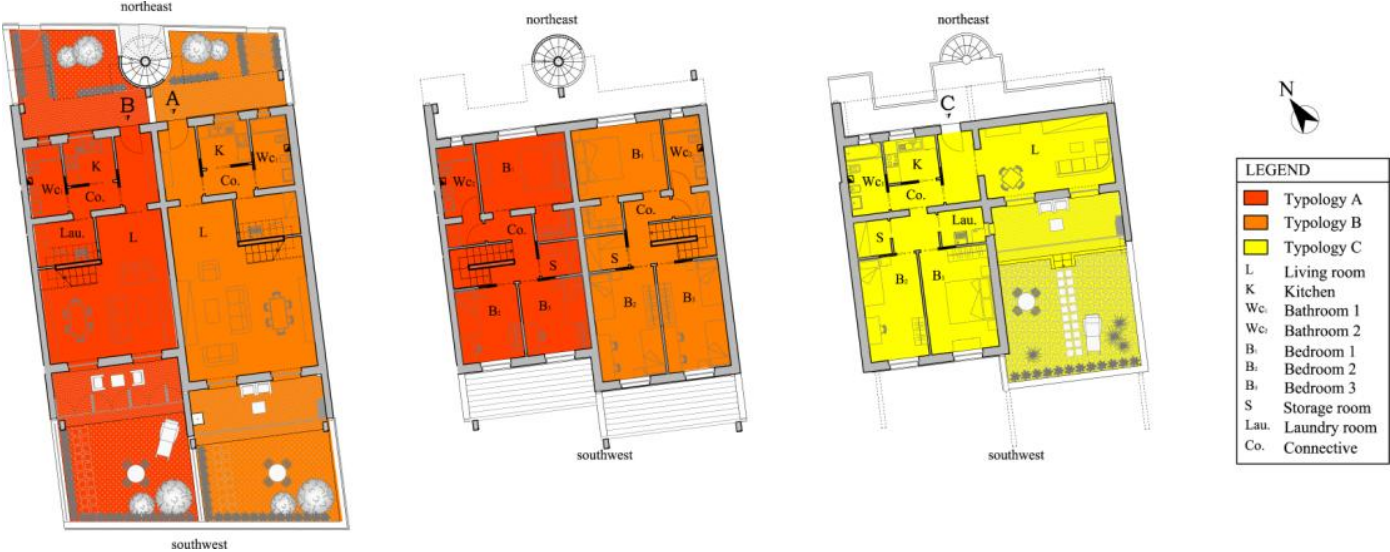

Fig. 9. Residential block: ground, first and second floor.
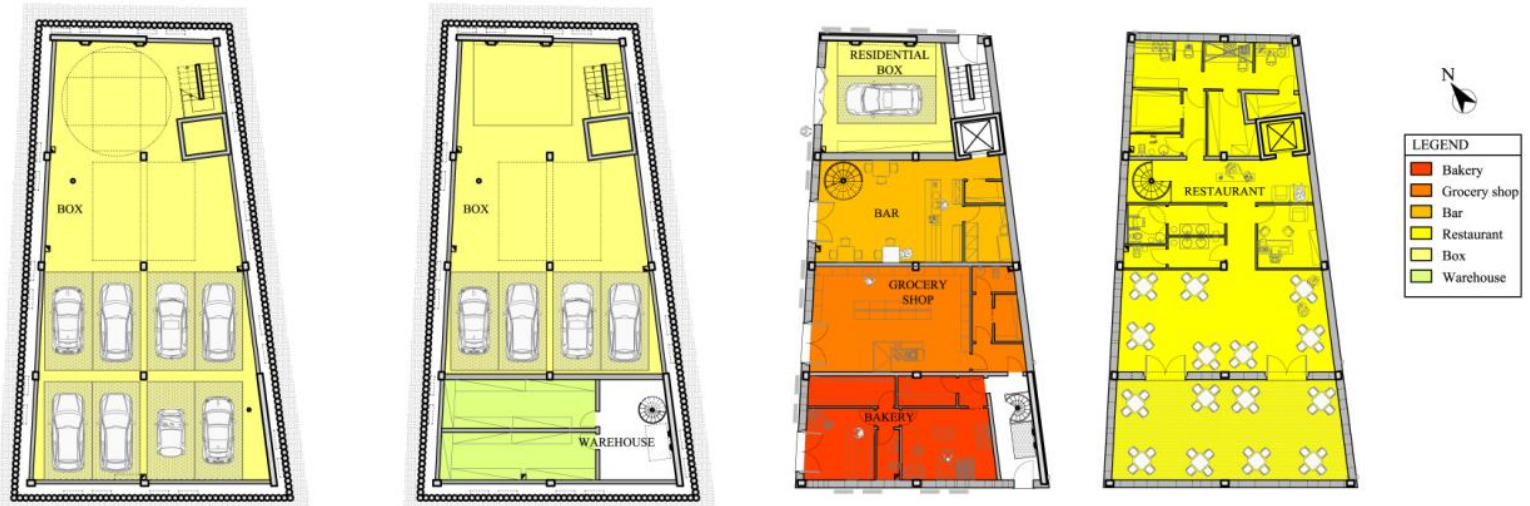

Fig. 10. Commercial block: double underground floor; ground and first floor.

The system takes over the car and keeps it until it is requested.

The parking area is located in a closed room, its gate is in the north-west side of the building; the system starts to work only if the room is closed from outside, so that it is absolutely sure that nobody is there. The waiting time is around five minutes, it depends on the number of the parked cars, at that moment.

\section{Building elements}

The two blocks that form the building are made in two different ways: the residential part is built in load-bearing reinforced masonry, while the commercial one has a reinforced concrete frame.

The first solution is more convenient with the massive envelope (we are going to describe). This type of building construction is not used in the commercial block because it has larger lights and two underground floors, that need a more flexible structure.

So also the foundation systems are different. In the residential part the system is formed by reinforced concrete curbs; under the commercial parts there is a grid of ground beam.
The link between the different depths is solved with a bulkhead.

All the external walls (load-bearing or not) are formed by clay block bricks $30 \times 25 \times 25 \mathrm{~cm}$, with vertical holes. In this way you have a massive envelope, very suitable for the Mediterranean climate.

As regard the coat insulation, the panels are fixed to the wall with adhesive mortar and with mechanical reinforcement.

The windows are with triple glass in the residential part and with double glass in the commercial one.

As to the green roof, it is necessary to cure the disposition of each element to assure the durability performance. The more critical parts are the waterproof of the corners and the folds.

\section{E. The plants}

One of the goals of the project is to use the renewable energy sources and minimizing the use of the traditional one. In order to reach to this aim the building is provided with a solar thermal plant to produce DHW, environmental heating or cooling [4] and a photovoltaic plant to produce electric energy.
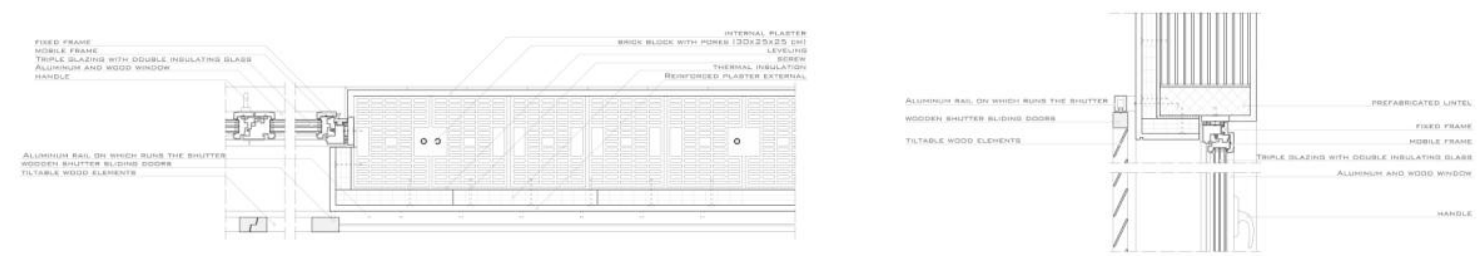

Fig. 11. Horizontal detail (on the left); vertical detail (on the right). 
The heating and the cooling of the rooms are obtained with a central system with radiant panels [3], for the residential areas, and a mixed air-water plant, with ventilconvector, for the commercial area.

The photovoltaic panels are set up on the wooden frames used to suspend the cantilever roof of the highest level. They are shaped to have the inclination of $30^{\circ}$, that is the best one for the latitude of the site.

The rainwater is a precious resource that usually is not used. In this building you have a plant to capture, collect, preserve and for the redistribution of it. The capitation is at the roof level of both blocks. The tank is underground and it empowers the sprinkler irrigation plant of the gardens.

The dimensioning of the plants was carried out after considering the thermo-hygrometric conditions of each block of the building (Tab. III).

In the end, on the base of all information, it was possible to evaluate the energy class of the designed building. We obtained an EPI of $8.8 \mathrm{KWh} / \mathrm{m}^{2}$.year, so the building is in A+ class.

\section{F. $\quad$ Architectonic aspects}

From the architectonic point of view the building has a contemporary character, it is not mimetic but it respects the volume proportions of the surrounding buildings. Its geometric simplicity is reinforced by a restricted number of colors used to define the elevation: the white of the plaster, the brown of the blinds and the grey of the steel elements.

Thanks to the redistribution of the built volumes it is possible to insert some green areas, despite the increase consequent to the Piano Casa.

\section{Conclusions}

The Piano Casa was adopted three years ago but it has been applied only in a restricted number of cases. The reasons of this not large success are two: the possibility of application only in a restricted area of the city and the economic crisis, that cuts down the investments in all European countries.

Very probably these difficulties are going to be removed: in fact a public movement of opinion is forming to introduce a correction in the law; moreover, in the opinion of economists, a period of economic recovery is nearing. Anyhow the Piano Casa is a really modern and updated regulation that encourages planners and owners to build more efficient buildings.

From this point of view it is really useful to show concrete examples and study cases to understand the best way to optimize the economic investment, in applying it. So you can be quite sure that the extra costs are lead to solutions able to reduce the energy consumption in a significant way.

Moreover it is clear that the good organization of the buildings, from an architectonical, constructive point of view, is the most important requirement to reduce the energy cost of them, especially in the Mediterranean climate.
In conclusion, the study here presented shows that the most significant qualities are the following:

- the employment of massive building envelope;

- the green roof;

- the control of sunlight (shading elements and reflective glasses);

- the use of free solar contributions (through the green houses);

- the use of renewable energy sources (solar thermal and photovoltaic plants);

- the reuse of rainwater.

We are going to carry out next steps of this study to obtain other confirms and to extend the results to other types of buildings.

Table III. - Data collected and adopted solutions.

\begin{tabular}{|l|c|c|}
\cline { 2 - 3 } \multicolumn{1}{l|}{} & $\begin{array}{c}\text { RESIDENTIAL } \\
\text { BUILDINGS }\end{array}$ & $\begin{array}{c}\text { COMMERCIAL } \\
\text { BUILDING }\end{array}$ \\
\hline $\begin{array}{l}\text { Thermal load in } \\
\text { summer }\end{array}$ & $\begin{array}{c}33.02 \\
\mathrm{~W} / \mathrm{m}^{2}\end{array}$ & $\begin{array}{c}45.67 \\
\mathrm{~W} / \mathrm{m}^{2}\end{array}$ \\
\hline Thermal load in winter & $\begin{array}{c}17.32 \\
\mathrm{~W} / \mathrm{m}^{2}\end{array}$ & $\begin{array}{l}17.25 \\
\mathrm{~W} / \mathrm{m}^{2}\end{array}$ \\
\hline $\begin{array}{l}\text { Useful energy demand } \\
\text { for DHW }\end{array}$ & $\begin{array}{c}26.29 \\
\mathrm{KWh} / \mathrm{m}^{2} \cdot \text { year }\end{array}$ & $\begin{array}{c}36.69 \\
\mathrm{KWh} / \mathrm{m}^{2} \cdot \text { year }\end{array}$ \\
\hline $\begin{array}{l}\text { Useful energy demand } \\
\text { for cooling and heating }\end{array}$ & $\begin{array}{c}23,82 \\
\mathrm{KWh} / \mathrm{m}^{2} \cdot \text { year }\end{array}$ & $\begin{array}{c}28,03 \\
\mathrm{KWh} / \mathrm{m}^{2} \cdot \text { year }\end{array}$ \\
\hline $\begin{array}{l}\text { Num. of thermal solar } \\
\text { panels needed }\end{array}$ & $11.15 \mathrm{~m}^{2}$ & $17.84 \mathrm{~m}^{2}$ \\
\hline $\begin{array}{l}\text { Num. of photovoltaic } \\
\text { panels needed }\end{array}$ & $31.8 \mathrm{~m}^{2}$ & $41.24 \mathrm{~m}^{2}$ \\
\hline
\end{tabular}

\section{References}

[1] Sapienza V., "Spontaneous architecture and energetic sustain-ability: the Aeolian homes of Filicudi Isle", in Proc. ZEMICH-2012.

[2] A. Gagliano, F. Patania, F. Nocera, A. Ferlito and A. Galesi, "Thermal performance of ventilated roofs during summer period“" Energy and Buildings (2012), pp. 611-618.

[3] F. Patania, A. Gagliano, F Nocera, and A. D'Amico "Low Energy Architecture and Reclaiming of Ancient Buildings: an Experimental Case of New Techniques of Air-conditioning", in Proc. PLEA 2004.

[4] F. Patania, A. Gagliano, F. Nocera, and A. Galesi, "Development of the solar cooling in the Mediterranean area", in Proc. PLEA 2011, pp. 639-644.

[5] F. Patania, A. Gagliano, F. Nocera, and A. Galesi "Building Renovation, Bio Architectural Techniques and Save Energy: an applied study-case in Kore University of Enna City (Italy)", in Proc. PLEA 2008.

[6] Directive 2010/31/EU of the European Parliament and of the Council of 19 May 2010 on the energy performance of buildings.

[7] Master Clima Aermec 113001.32 LE, Guida di MC Impianti 11300 (2010).

[8] IEA Solar Heating and Cooling Programme Task 20 "Solar Energy in Building Renovation" Subtask F: "Improvement of Solar Renovation Concepts and Systems". 